\title{
Pengukuran Kinerja Bank Perkreditan Rakyat Werdhi Sedana Kabupaten Gianyar Dengan Teknik Balanced Scorecard
}

\author{
Pande Made Hierra Andira Sari ${ }^{1}$ \\ I Ketut Suryanawa ${ }^{2}$ \\ ${ }^{1,2}$ Fakultas Ekonomi dan Bisnis Universitas Udayana (Unud), Bali, Indonesia \\ e-mail: hierraandira56@gmail.com
}

\begin{abstract}
ABSTRAK
Penelitian ini dilakukan pada BPR Werdhi Sedana dari tahun 2015 - 2017. Populasi seluruh karyawan dan nasabah BPR Werdhi Sedana. Sampel untuk karyawan diperoleh sejumlah 41 dan sampel untuk nasabah yang digunakan adalah 99 nasabah tabungan, 87 nasabah deposito dan 96 nasabah kredit. Teknik yang digunakan untuk mengambil sampel adalah simple random sampling. Teknik analisis data yang digunakan yakni perspektif - perspektif pada Balanced Scorecard. Perspektif keuangan mendapat hasil yang dikategorikan baik. Perspektif pelanggan dapat meningkatkan kepuasan pelanggan yang menghasilkan angka baik serta didukung peningkatan jumlah pelanggan. Perspektif bisnis internal menggunakan kapasitas infrastruktur yang mengalami penurunan dan pada pertumbuhan inovasi, BPR sudah mampu meningkatkan inovasi pada tahun 2018. Kemudian, perspektif pembelajaran dan pertumbuhan menunjukkan peningkatan produktifitas karyawan dan kepuasan karyawan.
\end{abstract}

Kata Kunci: Penilaian kinerja, balance scorecard.

\begin{abstract}
This research was conducted at BPR Werdhi Sedana from 2015 - 2017. The population is all employees and customers of BPR Werdhi Sedana. The sample for employees was 41 and the samples for customers used were 99 savings customers, 87 deposit customers and 96 credit customers. The technique used to take samples is simple random sampling.. The data analysis technique used is perspective on the Balanced Scorecard. The financial perspective got results that are categorized as good. The customer perspective can increase customer satisfaction that produces good numbers and is supported by an increase in the number of customers. The internal business perspective uses infrastructure capacity which has decreased and on innovation growth, BPR has been able to increase innovation in 2018. Then, the learning and growth perspective shows an increase in employee productivity and employee satisfaction.
\end{abstract}

Keywords: Performance assessment, balance scorecard.

\section{PENDAHULUAN}

Munculnya era pasar bebas membawa dampak persaingan bisnis yang semakin

ketat. Dalam hal ini semua perusahaan di Bali dituntut untuk bisa tetap bertahan dengan menyiapkan pengukuran kinerja yang harus selaras dengan visi dan misi perusahaan itu sendiri. Teknik yang tepat digunakan untuk mengukur kinerja 
perusahaan adalah konsep Balanced Scorecard. Dimana pengertian Balanced Scorecard (BSC) memberikan gambaran tidak adanya tumpeng tindih dalam target yang ingin dicapai saat ini maupun di masa mendatang terkait bidang keuangan maupun non-keuangan, atau dapat dikatakan dibutuhkan keseimbangan antar semua bagian perusahaan (Sony, 2007). BSC adalah alat yang memadai untuk memilih serangkaian indikator dan tujuan yang seimbang yang mencerminkan visi strategisorganisasi, membantu organisasi untuk memenuhi harapan pemangku kepentingan mereka, untuk mengartikulasikan danmengomunikasikan tujuan strategis dan untuk mengevaluasi implementasinya, mengubah misi dantujuan strategis menjadi tindakan, memungkinkan anggota untuk berkomunikasi satu sama lain dan merasakan kontribusi mereka(Quesado, et al., 2018). Tujuan untuk mengadopsi BSC atau variasinya adalah untuk menangkap data tentang apa yang telah terjadi dan untuk mengukurfaktor-faktor yang mendorong pertumbuhan yang menguntungkan (Ridwan, et al., 2013).

Perusahaan Daerah (PD) BPR Werdhi Sedana merupakan milik Pemerintah Kabupaten Gianyar. PD. BPR Werdhi Sedana merupakan badan usaha yang pelaksanaannya berada dibawah pengawasan, pengelolaan dan pembinaan kabupaten Gianyar, dan meupakan satu-satunya BPR milik kabupaten Gianyar. BPR Werdhi Sedana juga ditunjuk secara khusus oleh perbekel se-Kabupaten Gianyar sebagai pemegang Rekening Kas Desa (RKD).

Nilai lebih yang diciptakan bank diantara para nasabah dilakukan guna menunjukkan kinerja terbaik yang dapat diberikan oleh bank tersebut. Menurut Dave \& Dave, (2012) untuk mencipatakan nilai jual yang tinggi bagi bank kepada 
masyarakat, dapat dilakukan dengan beberapa cara seperti meningkatkan jumlah nasabah bank, memberikan solusi atau saran atau permasalahan yang dihadapi nasabah, dan mampu memberikan pelayanan yang berbeda dibandingan dengan yang lainnya. Hal yang tak kalah penting bagi sebuah bank adalah memiliki nasabah yang memiliki sifat loyal terhadap perusahaan kita yang dapat dicapai dengan cara berikut peningkatan dalam hal kualitas, baik itu kualitas pelayanan, kualitas produk, kualitas biaya manfaat, dan hal-hal lain terkait perbankan yang terus mengalami perkembangan mengikuti era modernisasi (Istiqlal, 2016).

Tepat jika dikatakan bahwa konsumen atau pembeli adalah raja. Kita membutuhkan mereka agar operasional perusahaan tetap bisa berjalan. Hal ini membutuhkan pelayanan yang terbaik yang harus diberikan agar konsumen mau dan menetap untuk menggunakan jasa kita dengan menggunakan strategi dan kinerja yang menitikberatkan pada kepuasan nasabah (Tahaka, 2011). Jadi setiap perbankan harus mampu memberikan pelayanan yang baik kepada setiap konsumennya agar konsumen tidak berpindah ke tempat lain, selain itu perlunya pelayanan yang baik agar citra perbankan itu sendiri baik dimata masyarakat sehingga mampu menarik lebih banyak konsumen.

BPR Werdhi Sedana merupakan salah satu Bank Perkreditan Rakyat yang belum pernah mengukur kinerja menerapkan BSC padahal BSC sangat diperlukan sebagai suatu penilaian kinerja yang nantinya diharapkan mampu mengevaluasi segala aspek pada perusahaan. Selain itu penerapan BSC sebagai alat ukur dalam kinerja BPR Werdhi Sedana diharapkan mampu mengukur kekurangan yang terjadi baik dari segi keuangan dan non keuangan, internal maupun eksternal, 
sehingga dapat dilakukan koreksi secepat mungkin untuk menjadi lebih baik lagi di masa yang akan datang.

BPR Werdhi Sedana merupakan BPR yang dipercaya langsung oleh kabupaten gianyar untuk memajukan perekonomian gianyar. Oleh karena itu diperlukan kinerja yang baik agar BPR Werdhi Sedana mampu memberikan pelayanan atau jasa sesuai dengan yang diharapkan oleh Pemerintah Gianyar. BPR Werdhi Sedana merupakan satu-satunya BPR milik pemerintah di Kabupaten Gianyar, untuk tetap menjaga eksistensinya di Kabupaten Gianyar, diperlukan suatu kinerja yang mampu bersaing dengan BPR lainnya. Oleh sebab itu diperlukan pengukuran kinerja yang tepat untuk memberikan arahan terhadap kinerja BPR Werdhi Sedana ke masa mendatang.

Dalam era modern sekarang ini, organisasi perbankan dihadapkan pada fokus tujuan untuk merancang strategi perencanaan, pengorganisasian, serta evaluasi kinerja yang maksimal agar memiliki nilai jual tinggi (Pratiwi, 2015). Kinerja menjadi salah satu ukuran efektif untuk mengukur prospek suatu perusahaan dari segi finansial maupun dari segi pelayanannya. Kinerja sejak dulu menjadi hal yang patut diberikan perhatian lebih bagi seluruh pelaku bisnis, dan wajib untuk terus ditingkatkan. Kinerja mengacu pada bagaimana perusahaan memberikan pelayanan dan menjamin keberlangsungannya masa mendatang. Kinerja digunakan dalam mengukur kemajuan organisasi dalam mencapai target kinerja periode sebelumnya, hal ini dilakukan untuk mengetahui target mana yang telah dicapai dan yang masih perlu dilakukan usaha untuk mencapainya. Dengan 
mengukur suatu kinerja, manajer dapat mengetahui apakah tingkat efesiensi dan efektifitas perusahaan sudah sesuai dengan apa yang diinginkan perusahaan.

Balanced Scorecard membantu dalam pengkomunikasian rencana bisnis dari manajer tingkat atas hingga sampai kepada para bawahan, sebab teknik tersebut merupakan cara/sistem yang sama bagi setiap anggota organisasi (Gunawan, 2009). Balanced Scorecard dapat dijadikan sebagai alat yang berperan dalam melakukan kontrol kinerja finansial perusahaan pada umumnya (Modell, 2004). BPR sendiri merupakan salah satu organisasi perbankan yang memiliki tujuan untuk melayani keuangan masyarakat.Tak mengherankan jika kesukseskan BPR dilihat dari bagaimana organisasi tersebut dalam pelayanan yang diberikan kepada nasabah.

Penelitian yang berkaitan dengan implementasi balanced scorecard juga pernah dilakukan oleh Hardiyanto, dkk., (2005) menguji Perancangan Dan Pembuatan Sistem Informasi Pengukuran Kinerja Pemasaran Dengan Metode Balanced Scorecard Studi Kasus PT. Semen Gresik. Penelitian lain dilakukan oleh Nor (2012) menguji tentang Penerapan Balanced Scorecard pada Pemerintah Daerah. Tujuan perusahaan menggunakan Balanced Scorecardpada dasarnya adalah untuk mempertahankan keberlangsungan organisasi di masa mendatang mengingat banyaknya pesaing yang bertumbuh (Aulia \& Andri, 2012).

Kinerja merupakan deskripsi terkait dengan tercapai atau tidaknya suatu program dalam melaksanakan kegiatan atau aktivitas dengan tujuan untuk mencapai target organisasi yang telah ditetapkan sebelumnya dalam proses perencanaan. Penilaian kinerja merupakan suatu tahapan dalam memberikan 
Pande Made Hierra Andira Sari dan I Ketut Suryanawa. Pengukuran ...

penilai terkait tingkat pelayanan yang diberikan oleh karyawan dalam mengerjakan tugas dan kewajibannya, yang pada akhirnya akan dijelaskan kepada para karyawan tersebut. Dessler (2004) dalam bukunya "Manajemen Sumber Daya Manusia” mengatakan penilaian kinerja dilakukan dengan memberikan perbandingan antara kinerja nyata dari para karyawan dengan standar maupun aturan yang telah ditetapkan perusahaan sebelumnya. Bank yang baik adalah bank yang mampu melaksanakan kewajibannya dengan lancar, memiliki keuangan yang sehat, dan mampu menarik kepercayaan masyarakat untuk menggunakan jasa mereka. Penumbuhan kepercayaan masyarakat dilakukan dengan membuat suatu ukuran kinerja demi memperoleh jawaban atas kinerja bank, kurang, masih perlu di tingkatkan, atau sudah benar-benar sehat, sehingga hal ini nantinya dapat menjadi bahan evaluasi perusahaan perbankan untuk mengatasi kekurangan yang ada. Kinerja diartikan sebagai hasil atau tujuan yang telah diperoleh atas usaha dalam memberdayakan sumber yang dimiliki perusahaan (Lizwaril, 2015).

Definisi Balanced Scorecard dinyatakan oleh Kaplan \& Norton (1996) yaitu suatu cara atau konsep yang memberikan penjelasan mengenai visi, misi perusahaan ke dalam sebuah ukuran khusus yang mejadi sebuah rancangan pengukuran sistem dan strategi manajemen.Pengertian Balanced Scorecard adalah kartu skor yang bermanfaat dalam proses penilaian kinerja baik dalam bidang finansial maupun di luar itu untuk operasi perusahaan saat ini dan di masa mendatang (Rangkuti, 2014). Teknik ini tidak hanya digunakan bagi perusahaan profit, melainkan juga dapat dimanfaatkan oleh perusahaan non-profit (Haeruddin, 2018). BSC menggunakan langkah-langkah keuangan untuk menentukan kinerja 
organisasi berdasarkan dimensi dan indikator penting. Ini termasuk: hubungan pelanggan, kompetensi inti, dan kemampuan organisasi (Fadhl Al-Hosaini \& Sofian, 2015). Sebagai alat manajemen, BSC membantu organisasi untuk menerjemahkan misi dan strategi mereka menjadi tujuan dan langkah nyata, dan juga menyeimbangkantindakan antara eksternal (keuangan - untuk pemegang saham dan pelanggan) dan tindakan internal (proses internal dan inovasi dan pembelajaran) (Stephen, et al.,2017).

Balanced scorecard dirancang sebagai hasil dari kebutuhan untuk memasukkan variabel non finansial untuk diukurkinerja suatu organisasi. Balanced scorecard mengubah rencana strategis organisasi dari dokumen yang menarik tetapi pasif ke dalam perintah berbaris untuk organisasi setiap hari (Malgwi \& Dahiru, 2014). Penerapan Balanced Scorecard memberikan keseimbangan antara berbagai perspektif yang akan memungkinkan organisasi untuk mengembangkan semua kapasitas organisasinya secara setara. Premis dasar dari hasil kartu seimbang untuk organisasi tidak membahayakan peluang masa depan mereka untuk bertindak, jika perspektif keuangan ditekankan untuk kepentingan perspektif strategis (Stefanovska \& Soklevski, 2014). BSC adalah alat yang diperlukan dalam desain dan pencapaian tujuan- kunci manajemen berkelanjutan dan pengendalian keputusan(Chiţu, et al., 2014).BSC harus mendesain peran bagaimana memahami pesan di antara setiap level secara efektif (Kopecka, 2015). Saluran komunikasi antarpribadi juga memainkan peranan penting dalam keberhasilan implementasidari BSC. Kepala setiap 
Pande Made Hierra Andira Sari dan I Ketut Suryanawa. Pengukuran ...

unit/departemen menjelaskan kepada stafnya tentang bagaimana BSC itudiimplementasikan (Zin, Sulaiman, et al., 2013).

Balanced Scorecard mengembangkan empat perspektif, diantaranya (1) perspektif pelanggan, (2) perspektif keuangan, (3) perspektif proses bisnis internal, dan (4) perspektif pembelajaran, dan pertumbuhan.Setiap perspektif menentukan tujuan strategis yang dapat memberikan keunggulan kompetitif bagi perusahaan. Tujuan strategis didorong oleh nilai-nilai inti, visi dan misi (Szóka, 2012). Keempat perspektif bertujuan untuk deskripsi lengkap tentang apa yang perlu Anda ketahui tentang bisnis. Pertama, ada dimensi waktu dari bawah ke atas. Keuntungan saat ini, dll. Sebagian besar mungkin merupakan konsekuensi dari apa yang duludilakukan kuartal terakhir atau tahun lalu; jika keterampilan baru ditambahkan sekarang, itu akan berdampak pada efisiensi dan keuangan tahun depan (Chavan, 2015). Keberhasilan implementasi BSC membutuhkan motivasi yang tinggikaryawan sehubungan dengan inisiatif serta tata kelola yang baikmanajemen dan praktik (Ayoup, et al., 2010).

Perpektif pelanggan menitikberatkan pada kepuasan pelanggan atas pelayanan yang kita berikan. Pelanggan merupakan sekelompok masyarakat yang membutuhkan jasa layanan atau konsumen sebuah produk. Lasdi (2002) menyatakan perspektif pelanggan memiliki 2 kelompok. Kelompok pertama yaitu kelompok pengukuran inti konsumen dengan beberapa hal sebagai tolok ukur yaitu pangsa pasar, retensi pelanggan, akuisisi pelanggan, tingkat kepuasan pelanggan, dan tingkat profitabilitas pelanggan. Kelompok kedua disebut sebagai kelompok pengukuran nilai konsumen yang memiliki tolok ukur sebagai berikut, 
atribut produk/jasa, hubungan pelanggan, image dan reputasi perusahaan beserta produk-produknya dimata para pelanggan dan masyarakat konsumen.

Ukuran keuangan sampai saat ini masih menjadi ukuran yang utama bagi konsumen dalam menilai sebuah perusahaan. Untuk itulah Balanced Scorecard tetap mempergunakan keuangan sebagai perspektif dalam pengukuran kinerja, sebab keuangan menjadi hal yang paling mudah digunakan untuk menilai keberlangsungan sebuah perusahaan di masa mendatang (Kaplan \& Norton, 1996). Pengguna Balanced Scorecard harus mengingat hal ini; alat ini bukan resep untuk sukses tetapi sarana yang dengannya bisnis dapat menilai arahnya, menyusun strategi, dan mendefinisikannya (Shadbolt, 2017). Perspektif keuangan di sisi lain mengukur penting terutama bagi organisasi yang berorientasi keuntungan terutama bagi pemegang saham dan investor (Ondieki, 2017). Proses bisnis internal dalam teknik Balanced Scorecard memiliki beberapa hal pokok, yaitu proses inovasi untuk menciptakan berbagai produk baru, proses operasional dengan tujuan meningkatkan kualitas dan menghemat waktu pembuatan produk, dan proses pelayanan yang dilihat dari pelayanan yang diberikan serta waktu dalam memberikan layanan tersebut.Perspektif pembelajaran dan pertumbuhan memiliki tugas untuk menyediakan sarana dan prasarana yang bertujuan untuk mencapai perspektif pelanggan, keuangan, dan bisnis internasional. Dengan adanya infrastruktur yang memadai, diharapkan ketiga perspektif yang lain juga mampu dicapai dengan baik.

Bisnis perbankan memiliki kewajiban dalam menghimpun dana masyarakat kemudian menyalurkannya kembali pada masyarakat. Dalam kata lain, perbankan 
merupakan perusahaan jasa yang memberikan pelayanan dalam hal keuangan pada masyarakat. Untuk itu, menjamin pelayanan yang terbaik bagi masyarakat adalah tugas utama organisasi perbankan. Dalam kaitannya sebagai organisasi bank, BPR Werdhi Sedana juga memiliki kewajiban utama dalam pemberian kualitas layanan terbaik kepada nasabah.Lima indikator pengukuran kinerja pokok yang setidaknya harus dimiliki perusahaan, diantaranya spesifik, dapat diukur, dapat dicapai, relevan, dan memiliki target waktu. Selain kesehatan finansial, sebuah perusahaan juga harus memiliki sumber daya modal, manusia, dan infrastruktur yang memadai, oleh karena itu sangat penting bagi perusahaan untuk menginvestasikan asetnya demi meningkatkan hal tersebut (Sarjono, dkk., 2010).

\section{METODE PENELITIAN}

Pendekatan kuantitatif digunakan dalam penelitian ini dengan pokok permasalahan yang dijelaskan secara deskriptif.

BPR Werdhi Sedana merupakan lokasi yang digunakan dalam penelitian ini, dengan menggunakan objek pelaksanakaan Balanced Scorecarduntuk memberikan penilaian terhadap kinerja bank.

Perspektif keungan menggunakan rasio keuangan untuk mengukur kinerjanya, antara lain Return on Asset (ROA), Beban Operasional terhadap Pendapatan Operasional (BOPO), Loan to Deposit Ratio (LDR). Variabel tingkat kepuasan pelanggan terhadap layanan bank diukur menggunakan skala likert. Adapun lima indikator yang digunakan, yaitu Reliability (Keandalan), Responsiveness (Cepat Tanggap), Assurance (Jaminan), Empathy (Empati), dan 
Tangible (Kasat Mata). Selain menggunakan kuesioner, perspektif pelanggan juga diukur dengan retensi pelanggan untuk memperoleh hasil apakah jumlah pelanggan mengalami peningkatan atau tidak. Dalam perspektif pembelajaran dan pertumbuhan variabel tingkat kepuasan dan motivasi karyawan akan diukur dengan skala Likert. Terdapat dua indikator yang digunakan, yaitu Atribut Kepuasan dan Atribut Motivasi Karyawan.

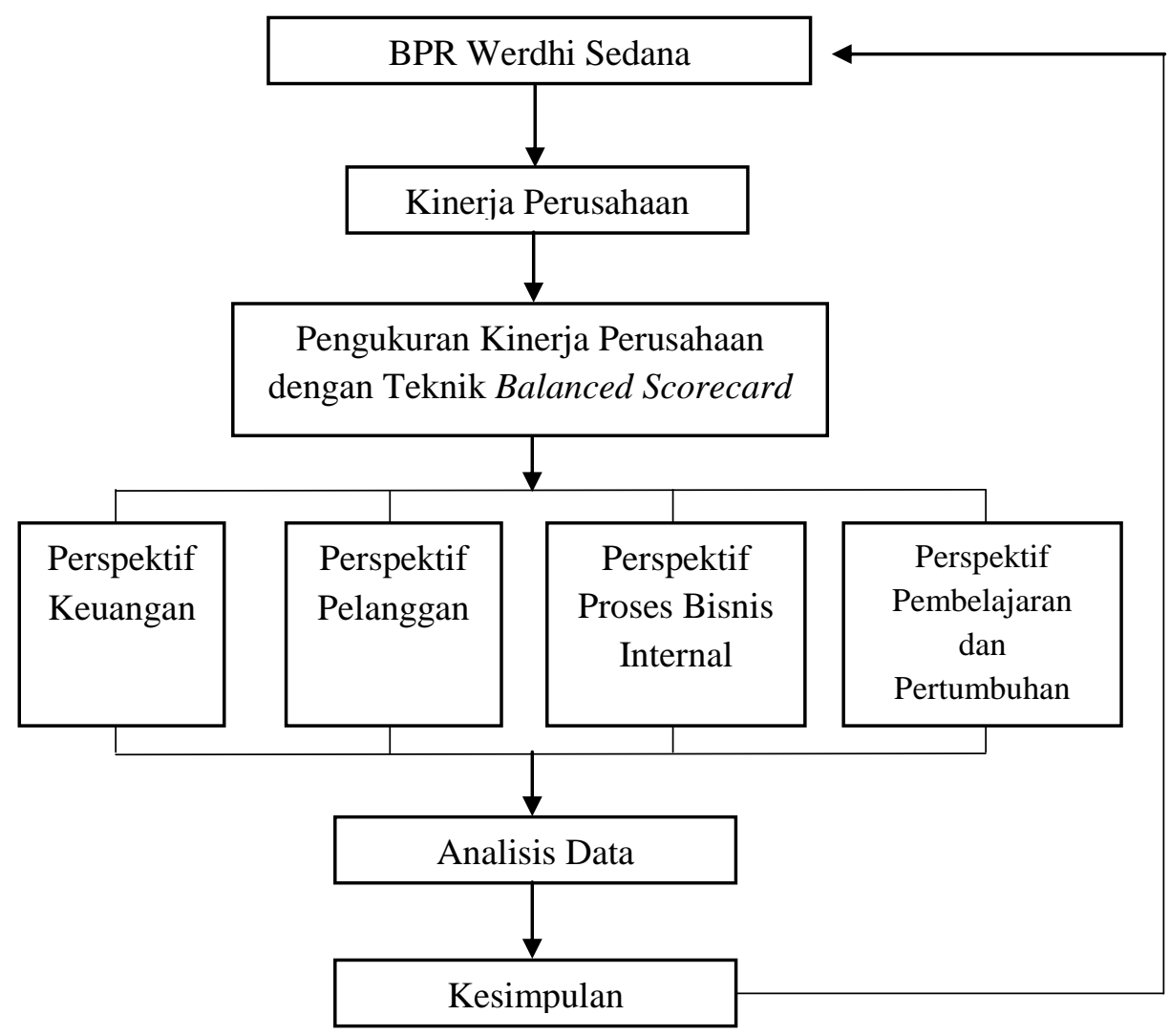

Sumber: Data diolah, 2018

\section{Gambar 1. Desain Penelitian}

Penelitian ini menggunakan karyawan BPR Werdhi Sedana dan seluruh nasabah sebagai populasinya. Jumlah karyawan adalah 41 orang, dan nasabah berjumlah 14.205 orang, yang terdiri dari 11.265 nasabah tabungan, 655 nasabah deposito dan 2285 nasabah kredit. Sampel ditentukan dengan menggunakan teknik non-probability sampling yaitu pemilihan sampel acak sederhana (simple random 
sampling).Untuk menentukan secara tepat jumlah sampel yang digunakan, peneliti menggunakan Rumus Slovin sebagai berikut:

$$
\mathrm{n}=\frac{\mathrm{N}}{1+\left(\mathrm{N} \cdot \mathrm{e}^{2}\right)}
$$

Keterangan :

$\mathrm{n}=$ Ukuran Sampel

$\mathrm{N}=$ Ukuran Populasi

$\mathrm{e}=$ Tingkat kesalahan (tingkat kesalahan yang ditetapkan adalah 10\% atau $0,1)$

Berdasarkan rumus (1), sampel nasabah diperoleh sebagai berikut:

$$
n=\frac{11.265}{1+\left(11.265 \cdot\left(0,1^{2}\right)\right)}=99 \text { orang }
$$

Jadi jumlah sampel untuk nasabah tabungan BPR Werdhi Sedana adalah 99 orang. Berdasarkan rumus (1), sampel nasabah dapat dihitung sebagai berikut:

$$
n=\frac{655}{1+\left(655 \cdot\left(0,1^{2}\right)\right)}=87 \text { orang }
$$

Jadi jumlah sampel untuk nasabah deposito BPR Werdhi Sedana adalah 87 orang. Berdasarkan rumus (1), sampel nasabah dapat dihitung sebagai berikut:

$$
n=\frac{2.285}{1+\left(2.285 \cdot\left(0,1^{2}\right)\right)}=96 \text { orang }
$$

Jadi jumlah sampel untuk nasabah kredit BPR Werdhi Sedana adalah 96 orang.

$$
\frac{\text { Laba Bersih }}{\text { Total Aset }} \times 100 \%
$$

Teknik analisis data yang digunakan adalah teknik Balanced Scorecarddengan empat perspektif. Perspektif keuangan menggunakan rasio 
keungan, yaitu pertama, dengan Return on Assets (ROA, diterangkan dalam rumus 2.

\section{Tabel 1.}

Predikat Kesehatan Berdasarkan ROA

\begin{tabular}{ccc}
\hline No & Rasio ROA & Predikat \\
\hline 1 & ROA $>1,5 \%$ & Sangat Sehat \\
2 & $1,25 \%<$ ROA $\leq 1,5 \%$ & Sehat \\
3 & $0,5 \%<$ ROA $\leq 1,25 \%$ & Cukup Sehat \\
4 & $0 \%<$ ROA $\leq 0,5 \%$ & Kurang Sehat \\
5 & ROA $\leq 0 \%$ & Tidak Sehat \\
\hline
\end{tabular}

Sumber :www.bi.go.id (2015)

Kedua, dilakukan dengan Beban Operasional terhadap Pendapatan Operasional (BOPO)

$$
\begin{array}{|l}
\text { Biaya Operasional } \\
\text { Pendapatan Operasional }
\end{array} 100 \%
$$

Menurut Bank Indonesia (2011) standar terbaik BOPO adalah kurang atau sama dengan $83 \%$.

Ketiga, dengan Loan to Deposit Ratio (LDR) dengan rumus sebagai berikut.

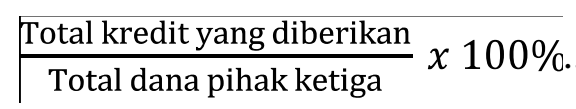

Tabel 2.

\section{Predikat Kesehatan Berdasarkan D}

\begin{tabular}{ccc}
\hline No & Rasio LDR & Predikat \\
\hline 1 & $50 \%<$ LDR $\leq 75 \%$ & Sangat Sehat \\
2 & $75 \%<$ LDR $\leq 85 \%$ & Sehat \\
3 & $085 \%<$ LDR $\leq 100 \%$ & Cukup Sehat \\
4 & $100 \%<$ LDR $\leq 120 \%$ & Kurang Sehat \\
5 & LDR $>120 \%$ & Tidak Sehat \\
\hline
\end{tabular}

Sumber : www.bi.go.id (2015)

Perspektif pelanggan diukur dengan mengetahui tingkat kepuasan pelanggan melalui penyebaran kuesioner, retensi pelanggan yang diketahui dengan menggunakan rumus: 
Retensi Pelanggan $\frac{\text { Jumlah Pelanggan tahun berjalan }}{\text { jumlah Pelanggan Tahun lalu }} \times 100 \%$

Perspektif bisnis internal diukur dengan Kapasitas Infrastruktur melalui tingkat pertumbuhan jumlah asset per tahun, dan Pertumbuhan Tingkat Inovasi dengan membagi jumlah produk baru dengan produk yang tersedia dikalikan dengan $100 \%$.

Perspektif pembelajaran dan pertumbuhan memfokuskan perhatian pada sumber daya manusia di organisasi, seperti meningkatkan kemampuan, keahlian, dan loyalitas karyawan (Riyana, 2017). Perspektif ini diukur dengan menilai kinerja karyawan melalui penyebaran kuesioner dan tingkat produktivitas karyawan dengan rumus.

$\frac{\text { Laba bersih sebelum pajak }}{\text { Jumlah Karyawan }} \times 100 \%$

\section{HASIL DAN PEMBAHASAN}

BPR Werdhi terletak di Jalan Ngurah Rai No 71 Gianyar, Bali. BPR Werdhi Sedana sama seperti oganisasi perbankan lainnya yang bergerak di bidang pelayanan kepada masyarakat.

Kuesioner sebanyak 282 buah telah disebarkan kepada nasabah BPR Werdhi Sedana dan telah terisi semua, begitupula sebanyak 41 buah yang disebar kepada seluruh karyawan.

Untuk memenuhi syarat validitas, maka butir pertanyaan harus memiliki Correlated Item - Total Correlation > 0,30 agar bisa lulus uji validitas. Uji validitas menunjukkan bahwa data bersifat valid. 
Tabel 3.

Hasil Uji Validitas

\begin{tabular}{cc}
\hline Variabel & Keterangan \\
\hline Nasabah Tabungan & Reliabel \\
Nasabah Deposito & Reliabel \\
Nasabah Kredit & Reliabel \\
Responden Perspektif Pembelajaran dan & Reliabel \\
Pertumbuhan & \\
\hline
\end{tabular}

Sumber: Data diolah, 2018

Nilai Cronbach Alpha > 0,60 digunakan sebagai dasar dalam menentukan reliabilitas instrument penelitian.

Tabel 4.

Hasil Uji Reliabilitas

\begin{tabular}{lcc}
\hline \multicolumn{1}{c}{ Variabel } & Nilai Cronbach's & Keterangan \\
& Alpha & \\
\hline Nasabah Tabungan & 0,768 & Reliabel \\
Nasabah Deposito & 0,726 & Reliabel \\
Nasabah Kredit & 0,716 & Reliabel \\
Responden Perspektif Pembelajaran dan & 0,795 & Reliabel \\
Pertumbuhan & & \\
\hline Sumer: Datar & & \\
\hline
\end{tabular}

Sumber: Data diolah, 2018

Analisis dari segi perspektif keuangan dengan pengukuran rasio keuangan berikut.

Tabel 6.

Return On Assets pada BPR Werdhi Sedana (Dalam Ribuan Rupiah)

\begin{tabular}{cccr}
\hline & 2015 & 2016 & \multicolumn{1}{c}{2017} \\
\hline Laba Bersih & 2.407 .696 & 2.095 .902 & 3.375 .003 \\
Total Aktiva & 75.842 .006 & 80.444 .347 & 103.029 .889 \\
ROA & $3,17 \%$ & $2,60 \%$ & $3,27 \%$ \\
Rata - Rata & & $3,01 \%$ & \\
\hline
\end{tabular}

Sumber : Data diolah, 2018

Kinerja BPR Werdhi Sedana dari tahun 2015 sampai 2017 masih tergolong baik karena berada di atas angka $1,5 \%$, baik dari masing-masing tahun maupun rata-rata tiga tahu tersebut. 
Tabel 7.

Beban Operasional terhadap Pendapatan Operasional pada BPR Werdhi Sedana

(Dalam Ribuan Rupiah)

\begin{tabular}{cccc}
\hline & 2015 & 2016 & \multicolumn{1}{c}{2017} \\
\hline Biaya Operasional & 5.519 .652 & 6.081 .794 & 6.289 .331 \\
Pendapatan & 8.823 .427 & 9.019 .317 & 11.347 .627 \\
Operasional & $62,56 \%$ & $67,43 \%$ & $55,42 \%$ \\
BOPO & & $61,80 \%$ & \\
Rata - rata & & & \\
\hline
\end{tabular}

Sumber : Data diolah, 2018

Rasio BOPO di atas memperlihatkan bahwa kinerja BPR Werdhi Sedana adalah baik karena besarannya kurang dari $83 \%$.

Tabel 8.

Rasio Loan to Deposit Ratio terhadap Pendapatan Operasional pada BPR
Werdhi Sedana
(Dalam Ribuan Rupiah)
(D)

Sumber : Data diolah, 2018

Bank Indonesia menyatakan bahwa kinerja perbankan yang dikatakan baik menurut rasio LDR berada antara $75 \%$ sampai dengan $85 \%$. Hal ini menunjukkan bahwa kinerja BPR Werdhi Sedana baik menurut rasio LDR.

Analisis dari perspektif pelanggan berdasarkan kepuasan pelanggan ditunjukkan dalam tabel berikut. 
Tabel 9.

Pernyataan Nasabah pada Perspektif Pelanggan BPR Werdhi Sedana Kepuasan Pelanggan

\begin{tabular}{ccc}
\hline & Positif & Negatif \\
\hline Nasabah Tabungan & $95,55 \%$ & $4,45 \%$ \\
Nasabah Deposito & $92,30 \%$ & $7,70 \%$ \\
Nasabah Kredit & $93,96 \%$ & $6,04 \%$ \\
\hline
\end{tabular}

Sumber : Data diolah, 2018

Tabel 8 menunjukkan bahwa nasabah merespon pelayanan BPR Werdhi Sedana dengan baik, semua golongan nasabah menganggap bahwa bank telah memberikan pelayanan yang sesuai dengan standar dansesuai dengan keinginan nasabah.

Retensi pelanggan merupakan segala cara atau kegiatan yang dilakukan oleh sebuah organisasi demi menjaga hubungan dan komunikasi yang baik dengan para pelanggannya.

Retensi Pelanggan $=\frac{\text { Jumlah Pelanggan tahun berjalan }}{\text { jumlah Pelanggan Tahun lalu }} \times 100 \%$.

$$
\begin{aligned}
& =\frac{14.205}{10.982} \times 100 \% \\
& =129,35 \%
\end{aligned}
$$

Dapat disimpulkan, dilihat dari retensi pelanggan BPR Werdhi Sedana memiliki peningkatan jumlah pelanggan, dimana hal ini menunjukkan pertumbuhan dari sebuah organisasi.

Analisis kinerja BPR Werdhi Sedana dilihat dari perspektif bisnis internal sebagai berikut, yakni dari segi kapasitas infrastruktur melalui pengukuran jumlah asset. 
Tabel 10.

Peningkatan atau Penurunan Jumlah Aset Tetap BPR Werdhi Sedana tahun $2015-2017$

(dalam ribuan rupiah)

\begin{tabular}{ccc}
\hline & Jumlah Aset Tetap & $\begin{array}{c}\text { Peningkatan Penurunan } \\
(\%)\end{array}$ \\
\hline 2015 & 783.177 & - \\
2016 & 950.608 & 21,38 \\
2017 & 714.271 & $-24,83$ \\
\hline
\end{tabular}

Sumber : Data diolah, 2018

Penurunan jumlah asset dari BPR Werdhi Sedana menunjukkan bahwa organisasi tersebut mengalami penurunan mutu pelayanan pada pelanggan.

Tabel 11.

Tingkat Pertumbuhan Inovasi pada BPR Werdhi Sedana

\begin{tabular}{ccc}
\hline Tahun & Jumlah Produk Baru & Jumlah Produk yang Ada \\
\hline 2015 & 0 & 6 \\
2016 & 0 & 6 \\
2017 & 0 & 6 \\
2018 & 1 & 7 \\
\hline
\end{tabular}

Sumber : Data diolah, 2018

Tabel 11 menunjukkan pengukuran tingkat pertumbuhan inovasi. Peningkatan produk pada tahun 2018 memperlihatkan bahwa memberikan pelayanan yang baik melalui penambahan jumlah produk yang baru. Hal ini berarti bahwa pada perspektif bisnis internal BPR Werdhi Sedana masih perlu meningkatkan dalam hal kualitas pelayanan yang diberikan kepada nasabah.

Pengukuran terakhir yaitu melalui perspektif pembelajaran dan pertumbuhan, yang pertama dengan mengukur tingkat produktivitas karyawan, sebagai berikut. 
Tabel 12.

Hasil Perhitungan Tingkat Produktivitas Karyawan (dalam ribuan rupiah)

\begin{tabular}{cccc}
\hline & Laba Bersih & $\begin{array}{c}\text { Karyawan } \\
\text { Keseluruhan }\end{array}$ & Total \\
\hline 2015 & 3.084 .695 & 35 & $88.134,14$ \\
2016 & 2.750 .709 & 39 & $70.531,00$ \\
2017 & 4.523 .436 & 41 & $110.327,71$ \\
\hline
\end{tabular}

Sumber :Data diolah, 2018

Pada tahun 2016 BPR Werdhi Sedana sempat mengalami penurunan produktivitas karyawan, namun hal ini nampaknya mampu diatasi terlihat dari perkembangan yang cepat di tahun berikutnya yang telah mengalami peningkatan dalam hal produktivitas karyawan.

Diukur dari tingkat kepuasan karyawan, kinerja BPR Werdhi Sedana adalah baik. Hal ini dikarenakan sebanyak $94,88 \%$ responden cenderung memberikan jawaban positif pada kuesioner. Hal ini memberikan kesimpulan bahwa kinerja BPR Werdhi Sedana dapat dikatakan baik dan sehat, sehingga nasabah dapat menjamin keamanan dari dana yang disimpan.

\section{SIMPULAN}

Kinerja BPR Werdhi Sedana secara keseluruhan tergolong baik. Teknik Balanced Scorecard melalui empat perspektif menunjukkan bahwa kinerja BPR ini sudah sesuai dengan standar dari Bank Indonesia. Perspektif keuangan, diukur melalui rasio ROA, BOPO, dan LDR menunjukkan angka yang baik dan memperlihatkan bahwa bank dalam kondisi sehat. Perspektif pelanggan yang diukur dengan kuesioner dan persentase retensi pelanggan juga menunjukkan angka yang baik. Dari perspekstif bisnis internal secara keseluruhan sudah tergolong baik, namun 
masih perlu ditingkatkan dalam hal mutu pelayanan yang masih kurang, yang terlihat dari penurunan jumlah asset tetap. Perspektif pembelajaran dan pertumbuhan juga memberikan hasil yang baik. Demi meningkatkan mutu pelayanan BPR Werdhi Sedana dapat menyediakan layanan ATM maupun mobile banking bagi para nasabah untuk mempermudah nasabah melakukan transaksi.

\section{REFERENSI}

Aulia, D., \& Andri, I. (2012). Perencanaan Strategi Pengembangan Usaha Kain Tenun Sutra dengan Pendekatan Metode Balanced Scorecard (Studi Kasus di Pabrik Sutra Tiga Putra). Jurnal Kalibrasi Sekolah Tinggi Teknologi Garut, 10(1), 1-12.

Ayoup, H., Omar, N. H., Kamal, I., \& Rahman, A. (2010). Implementation of Balanced Scorecard ( Bsc ) in a Malaysian Glc : Perceptions of Middle. AsiaPacific Management Accounting Journal, 7(2), 100-126.

Chavan, M. (2015). The balanced scorecard: A new challenge Journal of Management Development Article information: Journal of Management Development, 28(5), 393-406. https://doi.org/10.1108/02621710910955930

Chiţu, A., Elena OPRIŞ, M., \& Elena Opriş, M. (2014). Importance of Financial Perspective Indicators in Balanced Scorecard in a Leasing Company. Theoretical and Applied Economics, XXI(8597), 59-68. Retrieved from http://store.ectap.ro/articole/1010.pdf

Dave, D. S. R., \& Dave, D. S. R. (2012). Applying Balanced Scorecard in India Banking Sector: An Empirical Study of the State Bank of India. Pasific Business Review International, 5(6).

Dessler, G. (2004). Manajemen Sumber Daya Manusia (9th ed.). PT Indeks Kelompok Gramedia.

Fadhl Al-Hosaini, F., \& Sofian, S. (2015). A Review of Balanced Scorecard Framework in Higher Education Institution (HEIs). International Review of Management and Marketing, 5(1), 26-35. https://doi.org/2146-4405

Gunawan, K. (2009). Analisis Faktor Kinerja Organisasi Lembaga Perkreditan Desa di Bali (Suatu Pendekatan Perspektif Balanced Scorecard). Jurnal Manajemen Dan Kewirausahaan, 11(2), 172-182. Retrieved from 
http://puslit2.petra.ac.id/ejournal/index.php/man/article/view/17974

Haeruddin, M. I. M. (2018). Pengukuran Kinerja Perusahaan Dengan Menggunakan Balanced Scorecard pada PT . Pegadaian ( PERSERO) Cabang Talasalapang di Kota Makassar. Jurnal Aplikasi Manajemen, Ekonomi, Dan Bisnis, 2(2), 94-111.

Hardiyanto, Y., Holil, A., Ali, N., \& Arsa, H. (2005). Pengukuran Kinerja Pemasaran Dengan Metode Balanced Scorecard Studi Kasus Pt. Semen Gresik. Seminar Tugas Akhir.

Istiqlal, C. H. (2016). Penilaian Kinerja Perbankan Syariah Dengan Metode Balanced Scorecard. La_Riba, 3(2), 167-180. https://doi.org/10.20885/lariba.vol3.iss2.art3

Kaplan, R. S., \& Norton, D. P. (1996). Balanced Scorecard. Jakarta: Erlangga.

Kopecka, N. (2015). The Balanced Scorecard Implementation, Integrated Approach and The Quality of Its Measurement. Procedia Economics and Finance, 25(15), 59-69. https://doi.org/10.1016/S2212-5671(15)00713-3

Lasdi, L. (2002). Balanced Scorecard sebagai Rerangka Pengukuran Kinerja Perusahaan secara Komprehensif dalam Lingkungan Bisnis Global. Jurnal Widya Manajemen \& Akuntansi, 2(2), 150-169.

Lizwaril, R. (2015). Pengukuran Kinerja Koperasi dengan Balanced Scorecard. Jurnal Ilmiah Akuntansi Dan Humanika, 4(2), 1637-1654.

Malgwi, A. A., \& Dahiru, H. (2014). Balanced Scorecard financial measurement of organizational performance: A review. IOSR Journal of Economics and Finance, 4(6), 1-10.

Modell, S. (2004). Performance Measurement Myths in the Public Sector: A Reserach Note. Financial Accountability \& Management, 20(1), 0267-4424.

Nor, W. (2012). Penerapan Balanced Scorecard Pada Pemerintah Daerah. Jurnal Akuntansi \& Bisnis, 7(2), 280-292.

Ondieki, E. M. (2017). The Effect Of The Balanced SCcorecard On Organizational Performance In The Public Sector In Kenya: A Case Of Kenya Bureau Of Standars.

Pratiwi, A. (2015). Perbandingan Kinerja Perusahaan Dengan Pendekatan Balanced Scorecard pada BPR Syariah. Jurnal Ilmu-Ilmu Keislaman AFKARUNA, 11(1), 96-124. https://doi.org/10.18196/AIIJIS.2015.

Quesado, P., Guzmán, B. A., \& Rodrigues, L. L. (2018). Advantages and contributions in the balanced scorecard implementation. Intangible Capital, 
14(1), 186-201. https://doi.org/10.3926/ic.1110

Rangkuti, F. (2014). SWOT Balance Scorecard Teknik Menyusun Strategi Korporat yang Efektif Plus Cara Mengelola Kinerja dan Risiko. Jakarta: PT Centro Inti Media.

Ridwan, R., Harun, H., An, Y., \& Fahmid, I. M. (2013). The Impact of the Balanced Scorecard on Corporate Performance: The Case of an Australian Public Sector Enterprise. International Business Research, 6(10), 103-110. https://doi.org/10.5539/ibr.v6n10p103

Riyana, D. H. (2017). Pengukuran Kinerja Perusahaan PT INDOFOOD dengan Menggunakan Balanced Scorecard. Jurnal Sekuritas, 1(2), 42-53.

Sarjono, H., Pujadi, A., \& Wong, H. W. (2010). Penerapan Metode Balanced Scorecard sebagai Suatu Sistem Pengukuran Kinerja pada PT Dritama Brokerindo , Jakarta Timur. Binus Business Review, 1(1), 139-154.

Shadbolt, N. M. (2017). The Balanced Scorecard: A Strategic Management Tool for Ranchers. Massey University Journal. https://doi.org/10.2458/azu

Sony, Y. (2007). Petunjuk Praktis Penyusunan Balanced Scorecard Menuju Organisasi yang Berfokus pada Strategi (5th ed.). Jakarta: Gramedia Pustaka Utama.

Stefanovska, L., \& Soklevski, T. (2014). Benefits of Using Balanced Scorecard in Strategic and Operational Planning. Universal Journal of Management, 2(4), $165-171$.

Stephen, C., Kezzie, M., \& Rabiya, H. (2017). An evaluation of performance using the balanced scorecard model for the university of Malawis polytechnic. African Journal of Business Management, 11(4), 84-93. https://doi.org/10.5897/ajbm2016.8201

Szóka, K. (2012). The Significance of the Balanced Scorecard financial perspective - presented through the example of the AMOENA Medical Devices Trade and Provider Ltd. Journal of International Studies, 5(1), 8494. Retrieved from http://www.jois.eu/files/SzokaV5_N1.pdf

Tahaka, Y. C. (2011). Penerapan Balanced Scorecard Sebagai Alat Ukur Kinerja Pada Pt. Bank Sulut. Jurnal EMBA ISSN 2303-1174, 1(4), 402-413. https://doi.org/10.1183/09031936.00140408 
ISSN: 2302-8556

E-Jurnal Akuntansi

Vol.28.1.Juli (2019): 519-541

Zin, N., Sulaiman, S., Ramli, A., \& Nawawi, A. (2013). Performance Measurement and Balanced Scorecard Implementation : Case evidence of a Government-linked Company. Procedia Economics and Finance, 7(Icebr), 197-204. https://doi.org/10.1016/S2212-5671(13)00235-9 